\title{
ESTUDO PROSPECTIVO DE ESPÉCIES DE PEIXES DE ÁGUA DOCE COMO ALTERNATIVA PARA O PROCESSO DE ENLATAMENTO NA INDÚSTRIA DE CONSERVAS DE PESCADO
}

\author{
D.N. SOUSA ${ }^{1}$, P.C.M.S. CHICRALA ${ }^{2}$, C.R.F. PIRES ${ }^{3}$ \\ Embrapa Pesca e Aquicultura ${ }^{1,2}$, Universidade Federal do Tocantins ${ }^{3}$ \\ diego.sousa@embrapa.br ${ }^{1}$
}

Artigo submetido em 11/08/2017 e aceito em 28/09/2019

DOI: $10.15628 /$ holos.2019.6208

\section{RESUMO}

Nos últimos anos tem-se registrado uma alternância dos estoques naturais de sardinha, espécie primordial para as indústrias enlatadoras. Para assegurar a proteção de sua reprodução e garantir sempre altos estoques foi instituído o Período de Defeso. Assim, o objetivo deste estudo foi prospectar e traçar um panorama para a indústria de conservas de pescado acerca das espécies nativas de peixes de água doce, como alternativa para o processo de enlatamento, a fim de estimular a transferência de tecnologia para a produção de alimentos saudáveis e funcionais, que ainda não tem apelo comercial. Foram utilizadas as técnicas de avaliação de aceitabilidade e intenção de compra das espécies enlatadas de peixe matrinxã (Brycon amazonicus) e sardinha de água doce (Hemiodus unimaculatus). A matrinxã e a sardinha de água doce são espécies nativas promissoras como matéria-prima alternativa para a indústria conserveira de pescados, principalmente, para ocupar diferentes nichos de mercado, além de propiciar outras opções de alimento que garantam segurança alimentar à população menos favorecida.

PALAVRAS-CHAVE: Tecnologia, prospecção, matrinxã, sardinha de água doce.

\section{A PROSPECTIVE STUDY OF FRESHWATER FISH SPECIES AS AN ALTERNATIVE TO THE CANNING PROCESS IN THE CANNED FISH INDUSTRY}

\begin{abstract}
In recent years there has been an alternation of natural stocks of sardines, species. In recent years there has been an alternation of natural stocks of sardines, a primordial species for the canning industries. To ensure the protection of its reproduction and to always guarantee high stocks, the Period of Defense was instituted. Thus, the objective of this study was to prospect and outline the fish canning industry about native freshwater fish species as an alternative to the canning process in order to stimulate the transfer of technology for food
\end{abstract}

production Healthy and functional, that still does not have commercial appeal. The techniques of evaluation of acceptability and purchase intention of canned species of matrinxã (Brycon amazonicus) and freshwater sardines (Hemiodus unimaculatus) were used. Matrinxã and freshwater sardines are promising native species as an alternative raw material for the fish canning industry, mainly to occupy different market niches, as well as providing other food options that guarantee food security to the less favored population.

KEYWORDS: Technology, prospecting, matrinxã, freshwater sardines. 


\section{INTRODUÇÃO}

A produção brasileira de pescado atingiu média de 1.327 mil toneladas no período de 2013 a 2015, com uma projeção de 1.972 mil toneladas para o ano de 2025. No que se refere ao setor da aquicultura, a média de produção no país foi de 560 mil toneladas entre 2013 a 2015. Por sua vez, tem-se a previsão até o ano de 2025 mais que dobrar o cultivo de peixes, chegando a 1.145 mil toneladas. Contudo, apesar desse aumento na produção, o consumo nacional de pescado está em torno de 9,6 quilos per capta, estando abaixo dos 12 quilos recomendados pela Organização Mundial de Saúde (OMS). Tem-se a previsão de aumentar o consumo para 12,7 quilos per capta no ano de 2025 (FAO, 2016).

Observou-se no mercado brasileiro, no ano de 2013, o maior nível de importação de pescado, principalmente da China, Chile e Vietnã, passando de 151.464 toneladas em 2003 para 418.637 toneladas em 2013. Por conseguinte, ocorreu queda nos níveis de exportação do pescado brasileiro, passando de 113.838 em 2003 para 37.019 toneladas em 2013. Por outro lado, o pescado em conserva foi um dos produtos que mais tiveram aumento na importação (CONEPE, 2014).

A indústria de conserva no Brasil apresenta problemas graves de abastecimento, visto que a sua principal matéria-prima, que é a sardinha verdadeira, de origem extrativista, não atende a demanda do setor, o que tem provocado um alto grau de ociosidade e/ou a necessidade de importar pescado de outros países (Batista, 2005).

A sardinha verdadeira é a espécie de pescado mais popular entre os brasileiros. O consumo de sardinha enlatada nas regiões Nordeste e Norte do país é maior, por ser uma fonte de proteína animal acessível às populações de baixa renda dado ao seu preço acessível e garantia da segurança alimentar e nutricional. Sabe-se que ao longo dos últimos 40 anos, tem-se registrado um declínio em torno de $30 \%$ dos estoques naturais de sardinha. Para assegurar a proteção da sua reprodução foi instituído o Período de Defeso - Proibição da pesca durante três a cinco meses no ano variando de acordo com a bacia hidrográfica-, uma vez que não há estabilidade dos estoques, devido à grave situação da pesca excessiva dos cardumes em determinados períodos. Considerando que a incerteza quanto ao montante da captura de espécies de origem marinha, passíveis de serem enlatadas, representa um risco iminente para a indústria de conservas e que o abastecimento do mercado nacional por conservas de pescado importadas não traz benefícios socioeconômicos, é notória a busca por alternativas por meio da aquicultura.

Segundo informações da FAO (2016), a sardinha foi uma das espécies com destaque na produção no ano de 2013, mesmo considerando sua sobre explotação. Em relação às espécies identificadas como sardinha, tais como: sardinha verdadeira (Sardinella brasiliensis), lage (Opisthonemaoglinum) e boca torta (Cetengraulius edentatus), os dados apontam mais de 105 mil toneladas produzidas no Brasil, correspondendo a $13 \%$ de toda pesca extrativa. Considerando apenas a pesca marinha, a sardinha correspondeu a $18 \%$ da produção, destacando-se a sardinha verdadeira, que sozinha, respondeu por 14\% em 2011 (MPA, 2011). 
A indústria de enlatamento de pescado no Brasil se desenvolveu sobremaneira através do processamento de conservas da sardinha verdadeira em óleo vegetal. A aceitabilidade pela população do enlatamento dessa conserva e dos demais pescado perpassou por um produto de boa qualidade capaz de ser armazenado durante um tempo razoável após o processamento térmico adequado (Ogawa \& Ogawa, 1999) Este produto representou 95\% da produção total de enlatados na década de setenta. $O$ esforço da pesca e concentração do processamento sobre uma única espécie vem acarretando uma série de problemas do ponto de vista da disponibilidade de pescado e da relação com o consumo (Antunes, 1984). Cergola e Dias Neto (2011) ressaltam que houve grandes variações anuais da captura de sardinha verdadeira, com queda de $30 \%$ no período compreendido de 2009 a 2010. Isto se reflete na busca pela matéria-prima cada vez mais distante do local da industrialização.

A solução que vem sendo encontrada é a importação da sardinha verdadeira proveniente de países como Venezuela e Marrocos, o que onera ainda mais o custo da produção, podendo inviabilizar economicamente o processo do enlatamento pela indústria de conserva. Com isso, muitas indústrias conserveiras já encerraram suas atividades ou transferiram-se para outras regiões do país, na tentativa de se aproximar da matéria-prima ainda existente, como forma de diminuir os custos de produção e logística e, assim, dinamizar o processamento do pescado. A proibição da pesca no Período do Defeso gera alta dependência de matéria-prima importada, sendo um importante gargalo ao setor da indústria nacional de conserva de pescado. Além disso, verifica-se uma forte pressão internacional pela redução do imposto de importação da sardinha enlatada, o que representaria maior risco para o setor brasileiro.

O pescado é uma matéria prima estratégica para as indústrias de conserva de pescado, pois representa elemento relevante na contabilidade de custos dos produtos acabados (peixe enlatado), conforme relatou Beuren e Cardoso (2009).

Apesar do processo de enlatamento de pescado não ser uma novidade no Brasil e no exterior, alguns trabalhos têm sido realizados na busca de alternativas aos produtos convencionais como a sardinha e o atum (Alda, 2010). Carvalho e Lessi (1990), há duas décadas atrás, já justificavam a necessidade de um maior aproveitamento das diferentes espécies de pescado, por meio do uso de tecnologias, que permitam o uso racional dos recursos, sendo muitas delas inexploradas no âmbito comercial. Isso ainda não ocorreu, pois este tipo de produto requer o domínio de uma tecnologia específica adaptada as diferentes espécies nativas até então desconhecidas em nossas condições.

Em outra vertente, a piscicultura vem apresentando crescimento graças às novas técnicas de cultivo e manejo. Segundo Nhavoto (2016), os peixes de água doce criados em cativeiros são espécies em potenciais que podem ser utilizadas no processo de enlatamento. Contribui-se, para isso, que a industrialização de peixes de pequeno porte é uma opção para a redução dos custos em ração, além de que a uniformidade nos tamanhos dos peixes provenientes de piscicultura facilita a seleção do pescado a ser enlatado.

Espécies ainda não exploradas comercialmente para o enlatamento industrial, como a sardinha de água doce (Hemiodus unimaculatus), o lambari (Astyanax), tambaqui (Colossoma macropomum), a matrinxã (Brycon amazonicus) até mesmo alguns híbridos e espécies exóticas, 
como é o caso da tilápia (Oreochromis niloticus) têm grande potencial para serem utilizadas pela indústria enlatadora, por apresentarem características como sabor apreciado pelos consumidores, rápido crescimento e boa conversão alimentar. Voltado para o aproveitamento do pescado regional, Carvalho e Lessi (1990), optaram pelo uso de uma tecnologia simples, porém eficiente, para elaboração de uma semi-conserva de pescado. Este trabalho culminou na determinação de parâmetros para a obtenção de um produto adequado, aceitável e de boa qualidade com espécies de peixes de água doce nativas.

O estudo de Nhavoto (2016) realizou o enlatamento do tambaqui nos quais as conservas foram submetidas ao tratamento térmico de 30 minutos, o que evidenciou em uma boa descalcificação dos ossos. Na análise sensorial dessa conserva obtiveram aprovação de $100 \%$.

Carvalho e Lessi ( 1990) elaboraram semi conservas e indicaram que as espécies de peixes nativos de água doce utilizadas (Jaraqui, Curimatã, Dourado e Pirarucu) são mais adequadas para fabricação de marinado ou de picles de peixe, o que caracteriza este ser um outro tipo de produto em conserva.

A produção de conserva de tilápia na forma de "charuto" foi investigada por Batista (2005). O peixe foi colocado em salmoura e posteriormente pré cozido e coberto com molho de cobertura. Segundo o autor, a conserva de tilápia apresentou condições físico-químicas, nutricionais e sensoriais satisfatórias, o que confirma a viabilidade do produto para o mercado de conservas.

Em outro estudo, Dutra et al (2012) mencionaram que os entrevistados tiveram boa aceitação pelo produto enlatado (peixe de água doce), cuja maioria respondeu que a sardinha tradicional poderia ser substituída por outro pescado sem que houvesse rejeição sobre o produto. Das espécies testadas, o que mais se destacou em todos os requisitos foi o pacu, mostrando melhor aceitação em relação ao lambari e à tilápia, o que levou a ser mais bem avaliado para ser substituído pela sardinha. O lambari obteve uma aceitação inferior à do pacu, pois de acordo com a percepção dos entrevistados, apresentava aparência de peixe cru, cor esbranquiçada, paladar e aroma mais fracos e com muitos espinhos. A tilápia ficou em última preferência dos pesquisados em razão de ter um sabor mais forte e amargo quando comparado ao pacu.

Enquanto que no estudo de Alda (2010) comprovou a viabilidade técnica dos produtos filé de tilápia em conserva e patê à base de Carne Mecanicamente Separada de tilápia enlatada. Tanto a qualidade microbiológica quanto a nutricional, foram mantidas e obtiveram boa aceitação sensorial, comprovando o potencial de mercado e a forma alternativa para as indústrias especializadas em pescado.

Nesse panorama, o objetivo deste estudo foi prospectar e traçar um panorama para a indústria de conservas de pescado acerca das espécies nativas de peixes de água doce, como alternativa para o processo de enlatamento, a fim de estimular a transferência de tecnologia para a produção de alimentos saudáveis e funcionais, que ainda não tem apelo comercial. Para isso, foram utilizadas as técnicas de avaliação de aceitabilidade e intenção de compra das espécies enlatadas de peixe matrinxã (Brycon amazonicus) e sardinha de água doce (Hemiodus unimaculatus). 
A matrinxã, conhecida popularmente como piabanha, pode ser encontrada nas bacias do rio Amazonas, Tocantins e Araguaia. Este peixe do gênero Brycon, do qual também fazem parte a piracanjuba, a pirapitinga, a pirapitanga e a piabanha, vive em rios de águas claras, principalmente junto às pedras e troncos submersos, alimentando-se de pequenos frutos, sementes, insetos e pequenos peixes (Chicrala et al, 2013).

A carne da matrinxã é muito apreciada pelos consumidores, apesar da quantidade excessiva de espinhas, sendo mais consumida nas regiões Norte e Nordeste do país. Apresenta alto teor proteico e alto teor lipídico (acima de 15\%), característica esta observada principalmente em exemplares provenientes de criatórios É uma espécie da região amazônica com potencial para a indústria enlatadora devido ao crescimento precoce, atingindo o tamanho adequado para enlatamento (alevinão de 12 a $15 \mathrm{~cm}$ ) entre três a quatro meses de engorda. Em um ano, devido à boa conversão alimentar, a espécie chega a atingir de 800 gramas a 1,2 quilos de peso. Tais características vêm de encontro ao que se espera de uma determinada espécie para que seja recomendada para pisciculturas familiares, a fim de atender as demandas das indústrias conserveiras (Chicrala et al, 2013).

A sardinha de água doce mais conhecida por piau de escama fina, habita principalmente nas bacias dos rios Amazonas, Tocantins e Araguaia. Sobre esta espécie pouco se sabe em relação à participação no mercado tradicional de pescado, mas é sabido que pescadores tradicionais costumam se alimentar desse peixe de carne branca e textura firme. É uma espécie de pequeno porte, sendo que no rio Tocantins foram encontrados exemplares com tamanho entre $2,8 \mathrm{~cm}$ a $35,5 \mathrm{~cm}$, cujas fêmeas encontram-se em fase de reprodução entre os meses de junho a setembro. Esta espécie apresenta corpo fusiforme, com escamas visíveis, coloração prateada com uma mancha escura arredondada sobre a linha lateral (Chicrala et al, 2013).

\section{METODOLOGIA}

O pescado (matrinxã e sardinha de água doce) proveniente de cultivo em tanque escavado no Tocantins, foi adquirido de frigorífico com inspeção federal, congelado, acondicionado em caixas isotérmicas com gelo e enviado para o município de São Gonçalo (RJ) para o processo de enlatamento, feito por uma Fábrica de Conservas de Pescado com inspeção federal. No enlatamento utilizou-se cobertura de óleo vegetal (soja) para ambos as matérias primas e as latas apresentaram peso líquido de $125 \mathrm{~g}$ e peso drenado de $84 \mathrm{~g}$.

Foram adquiridos peixes dessas espécies do tamanho entre 13 a $17 \mathrm{~cm}$ que passaram por todas as etapas do processo de enlatamento na indústria. Ou seja, os peixes passaram por processo de descongelamento, recorte, salga, enlatamento, pré-cozimento, adição de óleo vegetal, recravagem e autoclavagem, de acordo com o que já ocorre com a linha de processamento da sardinha verdadeira na indústria em óleo comestível. O processo de enlatamento apresentou resultados satisfatórios. $\mathrm{O}$ produto do enlatamento foi enviado à Embrapa, onde foi submetido a testes de esterilização comercial.

Os pescados enlatados foram submetidos ao teste de análise sensorial para avaliar a aceitabilidade e a intenção de compra do produto pelo público avaliador. Este teste foi realizado em Palmas (TO), no Laboratório de Análise Sensorial da Universidade Federal do Tocantins, com 
60 julgadores não treinados, consumidores de pescado enlatado. As amostras foram codificadas com algarismos de três dígitos contendo 15 gramas de pescado que foram servidas para cada julgador, em cabines individuais iluminadas com luz fluorescente. No teste de aceitabilidade foram avaliados os atributos de aparência, aroma, sabor e impressão global. Utilizou-se a escala hedônica estruturada de nove pontos com notas entre um (desgostei muitíssimo) a nove (gostei muitíssimo) (Chaves \& Sproesser, 2002). Os provadores foram instruídos a julgar inicialmente a aparência dos produtos pela observação visual e depois aroma e sabor.

A intenção de compra do produto foi avaliada através de uma escala estruturada de cinco pontos, no qual a nota um é relacionada a certamente não compraria e a nota cinco está atrelada a certamente compraria (Chaves \& Sproesser, 2002). Para os testes sensoriais foi mantido o máximo de individualidade necessária para a avaliação das amostras pelos provadores. A equipe de aplicação foi responsável pelo controle, transmissão de instrução e orientação geral dos testes.

Os dados da análise sensorial foram analisados por meio do cálculo da frequência e média que foram apresentados na forma de tabelas e histogramas.

\section{RESULTADOS E DISCUSSÕES}

No teste realizado foram analisadas duas espécies nativas de peixe que foram comparadas em relação aos aspectos sensoriais: aparência, aroma, sabor e impressão global. Esses atributos foram classificados em três faixas de referências: notas de 1 a 4 (faixa que corresponde a desgostar do produto), nota 5 (indiferente) e notas entre 6 a 9 (faixa que corresponde a gostar do produto). Entre os apontamentos do estudo, verificou-se que a maioria (aproximadamente 70\%) dos provadores atribuíram notas entre seis e nove, o que corresponde aos termos gostei ligeiramente e gostei muitíssimo para todos os atributos avaliados nas amostras de sardinha de água doce e matrinxã. Esses dados serão analisados com mais detalhes abaixo.

Na avaliação do atributo aparência, a amostra matrinxã obteve nota média de 6,52 e a amostra de sardinha de água doce nota média de 6,17 situando entre os termos "gostei ligeiramente e gostei moderadamente" (Tabela 1).

Tabela 1- Notas médias dos atributos cor, aroma, sabor, impressão global e intenção de compra das amostras de sardinha de água doce e matrinxã enlatadas.

\begin{tabular}{l|l|l|l|l|l}
\hline \multicolumn{1}{c|}{ Pescado } & \multicolumn{1}{|c|}{ Cor } & \multicolumn{1}{c|}{ Aroma } & \multicolumn{1}{c|}{ Sabor } & \multicolumn{1}{c}{$\begin{array}{c}\text { Impressão } \\
\text { Global }\end{array}$} & $\begin{array}{c}\text { Intenção de } \\
\text { Compra }\end{array}$ \\
\hline Matrinxã & 6,52 & 6,40 & 7,13 & 6,73 & 4,08 \\
\hline $\begin{array}{l}\text { Sardinha de } \\
\text { água doce }\end{array}$ & 6,17 & 6,50 & 6,67 & 6,38 & 3,48 \\
\hline
\end{tabular}

Observou-se que $76,67 \%$ e $75 \%$ dos consumidores deram nota superior a seis, para as amostras de sardinha de água doce e matrinxã, respectivamente. Quanto às notas mínimas, abaixo de quatro, a sardinha de água doce obteve um percentual de $18,33 \%$ enquanto que a matrinxã 
15\% (Figura 1). Santos et al (2015) realizaram a análise sensorial da espécie matrinxã e a aparência/cor foi o item menos aceito com a nota 6,10, o que correspondeu a categoria "gostei ligeiramente". Este fato foi justificado pelos provadores que relataram que a matrinxã tinha o aspecto turvo e a presença de mancha no corpo, característica específica da espécie que lembra o formato de um olho.

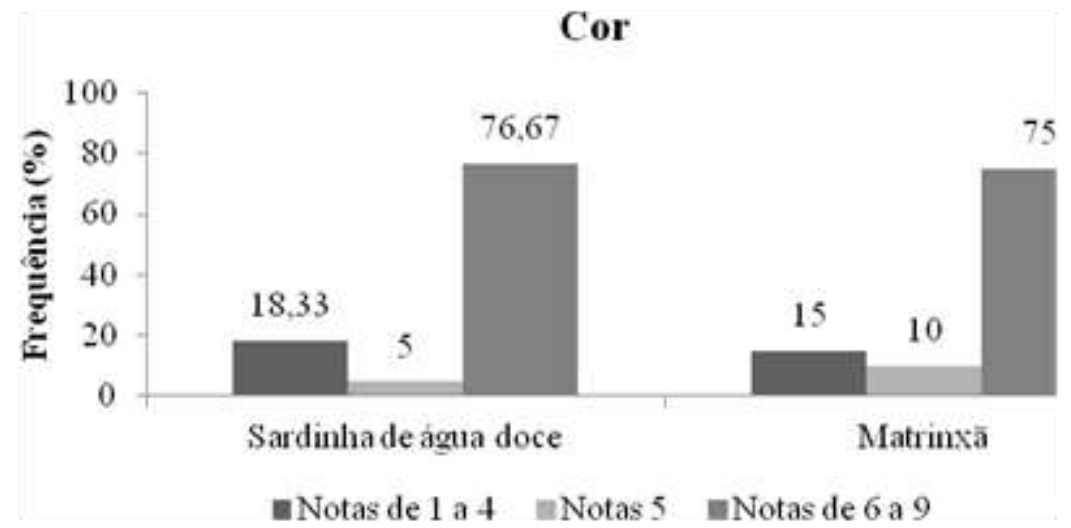

Figura 1. Notas atribuídas ao aspecto cor.

Com relação a avaliação do aroma observou-se que as notas médias para este atributo variaram entre 6,40 e 6,50 para as amostras de matrinxã e sardinha de água doce, respectivamente (Tabela 1). 76,67\% dos consumidores atribuíram notas entre 6 e 9 para a amostra de sardinha de água doce, enquanto para a matrinxã este percentual foi $5 \%$ mais baixo. A matrinxã também apresentou maior percentual de notas entre 1 e 4 quando comparado aos valores obtidos para a amostra de sardinha de água doce (Figura 2).

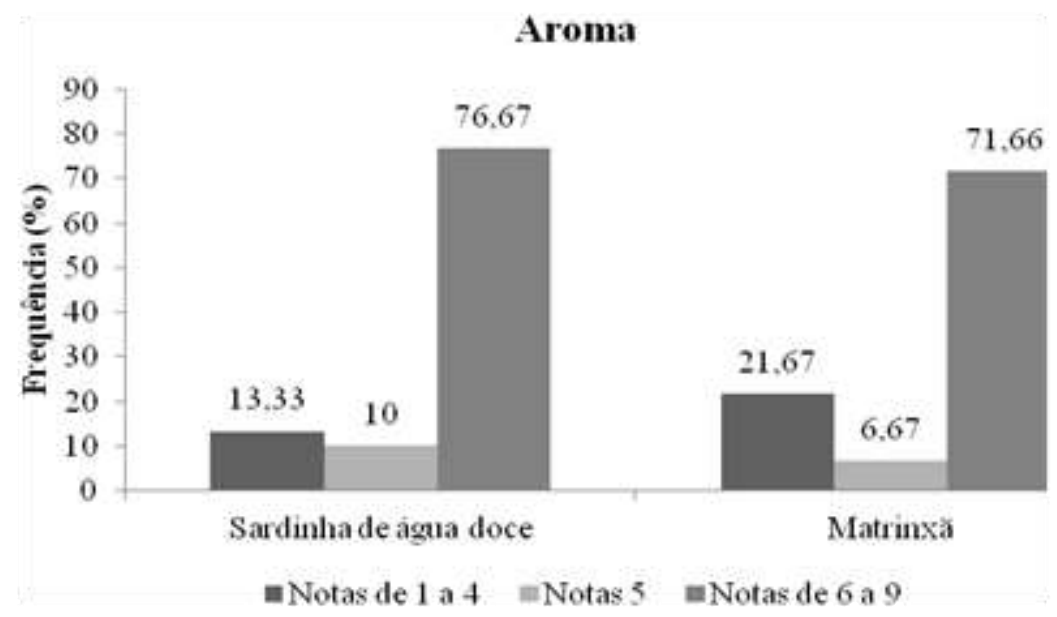

Figura 2. Notas atribuídas ao aspecto aroma.

Na avaliação do aspecto sabor observou-se que a espécie melhor avaliada foi a matrinxã, onde $83,34 \%$ dos provadores atribuíram notas entre 6 e 9 (Figura 3). A nota sensorial média do pescado matrinxã foi de 7,13 para este atributo, situando entre os termos "gostei moderadamente e gostei muito" (Tabela 1). É válido destacar que apenas 8,33\% dos provadores registraram notas 
entre 1 e 4 para o pescado matrinxã, enquanto para a amostra sardinha de água doce mais de $20 \%$ dos provadores atribuíram notas na faixa de desgostar do produto.

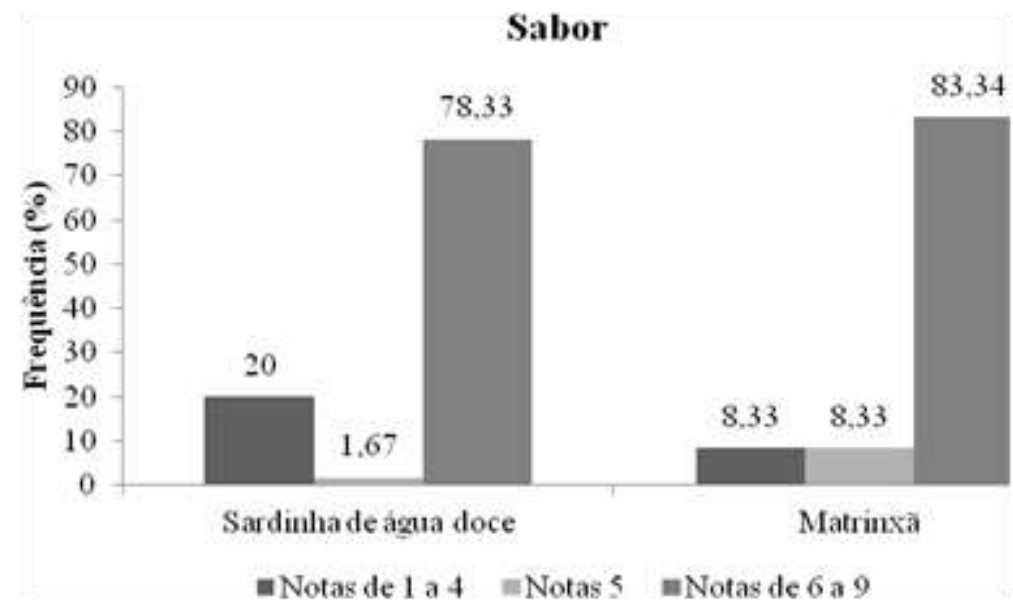

Figura 3. Notas atribuídas ao aspecto sabor.

Na avaliação sobre a impressão sensorial global das espécies, 78,33\% dos provadores deram notas entre 6 e 9 para a amostra de sardinha de água doce (Figura 4). A nota média encontrada para a sardinha de água doce para o atributo impressão global foi de 6,38 (Tabela 1). Maior percentual de aceitação foi encontrado para a amostra de matrinxã (85\%). Quanto as notas mais baixas, identificadas pela variação entre 1 e 4, para a sardinha de água doce, 16,67\% dos provadores afirmaram desgostar deste pescado enquanto para a matrinxã apenas $6,67 \%$ dos provadores desgostaram do produto enlatado.

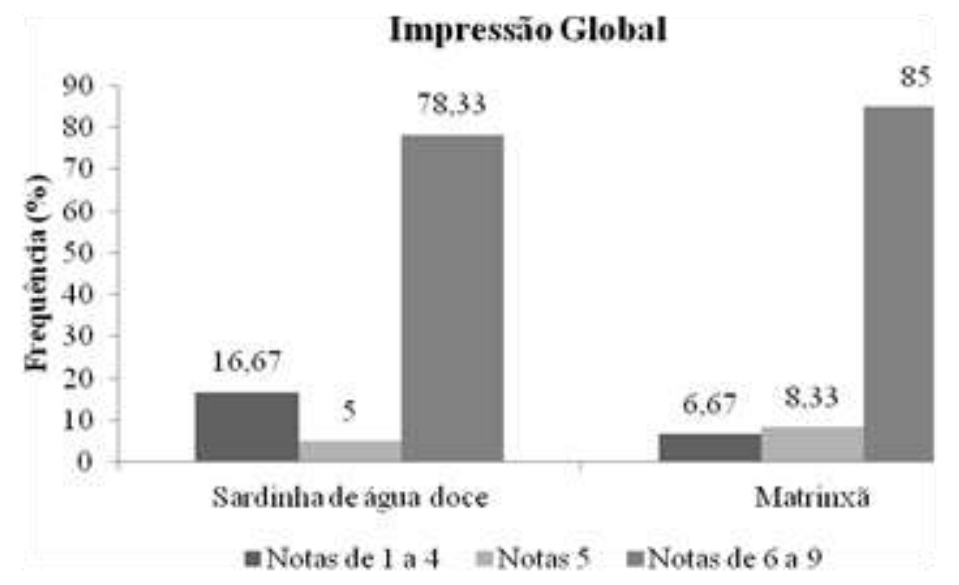

Figura 4. Notas atribuídas a impressão global.

Santos et al (2015) observaram que $48 \%$ dos consumidores deram nota máxima (gostei muitíssimo) para o atributo impressão global para a matrinxã, enquanto que apenas $2 \%$ dos provadores deram nota um (desgostei muitíssimo).

Com relação à intenção de compra da sardinha de água doce enlatada, observou-se que a mesma apresentou valor médio de 3,48 situando entre os termos "Não sei e provavelmente 
compraria". Aproximadamente $28,33 \%$ dos julgadores afirmaram que comprariam certamente, $36,67 \%$ provavelmente comprariam, enquanto que 13,3\% afirmaram que certamente não compraria , 10\% afirmaram que provavelmente não comprariam e 11,67\% não opinaram. Já a matrinxã, obteve nota média de 4,08, o que corresponde aos termos "provavelmente compraria e certamente compraria". 46,67\% dos julgadores afirmaram que comprariam certamente, 40\% disseram que provavelmente comprariam, enquanto que apenas $6,67 \%$ disseram que certamente não compraria, 3,33\% \% afirmaram que provavelmente não comprariam e o mesmo índice de julgadores não opinaram.

\section{Intenção de Compra}

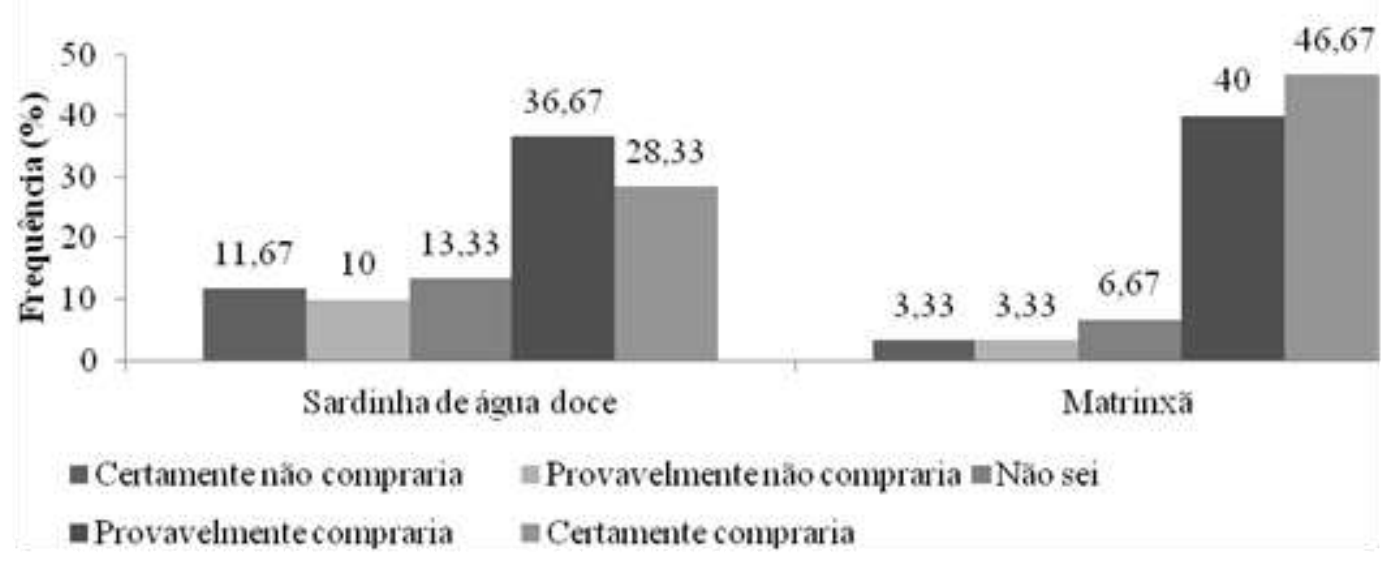

Figura 5. Notas atribuídas a intenção de compra.

Portanto, quanto à intenção de compra pode-se afirmar que a matrinxã apresentou maiores valores percentuais de intenção de compra (provavelmente compraria e certamente compraria) quando comparada à sardinha de água doce.

\section{CONCLUSÃO}

As espécies de peixe prospectadas apresentam perspectivas de serem comercializadas com boa aceitação pelo mercado e possibilidade de dinamizar o setor das indústrias de conservas a partir da introdução de novas espécies e criação de novos nichos de mercado.

A utilização de matéria-prima, oriunda da aquicultura, para a indústria de conservas permite maior constância no fornecimento devido à possibilidade de planejamento da despesca, para o atendimento da demanda da indústria, além de contribuir para a redução dos problemas relacionados à pesca extrativa. 


\section{REFERÊNCIAS}

ANTUNES, S. A. (1984) Processamento, parâmetros de qualidade e espécies de atuns e bonitos no desenvolvimento da indústria de enlatamento de pescado no Brasil. Brasília, DF: SUDEPE.

BATISTA, L. X. (2005) Tecnologia de produção de conserva de tilápia (Oreochromis niloticus, Linnaeus, 1758 - Linhagem chitralada). 38f. Dissertação (Mestrado em Recursos Pesqueiros e Aquicultura) - Programa de pós-graduação em recursos pesqueiros e aquicultura, Universidade Federal Rural de Pernambuco.

BEUREN, I.M; CARDOSO, R. S. (2009) Gestão de matérias-primas em indústrias de conserva de pescado do Brasil e da Espanha. Anais do XVI Congresso Brasileiro de Custos. UFCE: Fortaleza/CE.

CARVALHO, N. L. A; LESSI, E. (1990) Elaboração de uma semi-conserva de pescado de água doce "Picles de Peixe": Tempo de cura, acidificação, textura e nível de sal. Acta Amaz., 20:321-329.

CERGOLA, M. C; DIAS NETO, J. (2011) Plano de Gestão para o Uso Sustentável da Sardinhaverdadeira do Brasil. In: CERGOLA, M, C; DIAS NETO, J. (Orgs). Série Plano de Gestão dos Recursos Pesqueiros. Brasília-DF: Ibama. Disponível em <http://www.ibama.gov.br/phocadownload/plano gestao sardinha verdadeira 2011.pdf >. Acesso em: 31 jan. 2017.

CHAVES, J. B. P; SPROESSER, R. L. (2002) Práticas de laboratório de análise sensorial de alimentos e bebidas. 1a ed. Viçosa: UFV.

CHICRALA, P. C. M. S; LIMA, L. K. F; MORO, G. V; NEUBERGER, A. L; MARQUES, E. E; FREITAS, I. S. (2013) Catálogo de peixes comerciais do lago da Usina Hidrelétrica Luís Eduardo Magalhães. Brasília-DF: Embrapa. Disponível em <https://www.embrapa.br/pesca-e-aquicultura/buscade-publicacoes/-/publicacao/995263/catalogo-de-peixes-comerciais-do-lago-da-usinahidreletrica-luis-eduardo-magalhaes-tocantinsbrasil>. Acesso em: 15 abr. 2017.

Conselho Nacional de Pesca e Aquicultura - CONEPE. (2014) Relatório exportações e importações brasileiras de pescado. Brasília: Conepe.

DUTRA, F. M; MACHADO, W. J; CAETANO, M, S; GOBBO, D. A. (2012) Avaliação sensorial do processamento em conserva, utilizando-se as espécies: tilápia (Oreochromis niloticus), lambari (Astianax spp) e pacu (Piaractus mesopotamicus). Revista Brasileira de Produtos Agroindustriais, 14 (3):239-244.

Food and Agriculture Organization of the United Nation - FAO. (2016) The state of world fisheries and aquaculture. Roma: FAO. Disponível em <http://www.fao.org/3/ai5555e.pdfhttp://www.fao.org/3/a-i5555e.pdf>. Acesso em: 12 jul. 2017.

MINISTÉRIO DA PESCA E AQUICULTURA - MPA. (2011) Boletim estatístico da pesca e aquicultura Brasil 2010. Brasília-DF: MPA. Disponível em <http://sinpesq.mpa.gov.br/preps_cms/download/boletim_2010/boletim_estatistico mpa 2010.pdf>. Acesso em: 10 ago. 2015. 
MUNOZ, A. E. P; SANTOS, V. R. V; SOUSA, D. N; CHICRALA, P. C. M. S. (2015) Viabilidade econômica da matrinxã como alternativa de matéria-prima à sardinha para o mercado de conservas de $\begin{array}{lllll}\text { pescado. Série Documentos } & \text { Embrapa, }\end{array}$ Disponível em $<$ https://www.infoteca.cnptia.embrapa.br/infoteca/bitstream/doc/1023020/1/CNPASADoc9 .pdf>. Acesso em: 15 de abr. 2017.

OGAWA, M; OGAWA, N. B. P. Enlatamento (1999). In: Manual de pesca. OGAWA, M; MAIA, E. L. (Orgs). São Paulo: Livraria Varela, 324-335.

SANTOS, V. R. V; FREITAS, D. G. C; CHICRALA, P. C. M. S; SOUSA, D. N; FURTADO, A, A, L; LUIZ, D. B. (2015) O matrinxã como alternativa para enlatamento: avaliação da aceitação e da intenção de compra. Série Documentos Embrapa, 12 (20): 1-24. Disponível em <http://ainfo.cnptia.embrapa.br/digital/bitstream/item/128871/1/CNPASA-Doc12.pdf>. Acesso em: 15 abr. 2017. 